This is the post print of a published manuscript in ACS Earth and Space Chemistry (2019) https://doi.org/10.1021/acsearthspacechem.8b00197 


\title{
Direct observations of the coupling between quartz dissolution and $\mathrm{Mg}$-silicate formation
}

\author{
Lisa de Ruiter ${ }^{1 *}$, Christine V. Putnis ${ }^{2,3}$, Jörn Hövelmann ${ }^{4}$, Helen E. King ${ }^{5}$ \& Håkon Austrheim ${ }^{1}$ \\ ${ }^{1}$ Physics of Geological Processes (PGP), The Njord Centre, Department of Geosciences, University of Oslo, 0136 Oslo, Norway \\ ${ }^{2}$ Institut für Mineralogie, Universität Münster, 48149 Münster, Germany \\ ${ }^{3}$ Department of Chemistry, Curtin University, Perth 6845, Australia \\ ${ }^{4}$ German Research Centre for Geosciences (GFZ), Interface Geochemistry, 14473 Potsdam, Germany \\ ${ }^{5}$ Department of Earth Sciences, Utrecht University, 3584 CB Utrecht, the Netherlands
}

*Corresponding author: 1.d.ruiter@fys.uio.no

\begin{abstract}
Although quartz is a stable mineral at Earth surface conditions, field samples have shown its rapid dissolution in combination with the precipitation of $\mathrm{Mg}$-silicate phases. Atomic force microscopy (AFM) experiments were performed to investigate the dissolution of quartz and the precipitation of secondary phases in high-pH, Mg-rich solutions both in-situ and ex-situ. Experiments were conducted at room temperature with varying $\mathrm{MgCl}_{2}$ or $\mathrm{MgSO}_{4}$ concentrations (0.1-100 mM), $\mathrm{pH}(8.9-12)$ and ionic strength $(<1-530 \mathrm{mM})$. The results suggest that quartz dissolves by the removal of nanoparticles on the time scale of minutes, and that a nm-scale gel-like layer of amorphous silica forms on the quartz surface and is thicker at higher $\mathrm{pH}$. During the in-situ experiments, soft and poorly attached precipitates form on the surface when the $\mathrm{Mg}$ concentration is high $(100 \mathrm{mM})$. After 20 hours in a high-pH, Mg-rich solution, solid Mg-rich precipitates can be observed at places on the surface where the gel-like silica layer is present, predominantly near surface edges where dissolution is enhanced. This suggests a coupling between the dissolution of quartz, that resulted in the gel-like layer, and the formation of secondary phases, indicating an interface-coupled dissolution-precipitation mechanism. The precipitates could not be
\end{abstract}


precisely identified but evidence suggests they are likely to be amorphous $\mathrm{Mg}$-silicate phases. Such a coupled reaction may provide a pathway for $\mathrm{Mg}$-Si phase formation suitable as a new environmentally friendly cement.

\section{Introduction}

Quartz is known as one of the most stable minerals at Earth-surface conditions, and thus relatively resistant to chemical weathering. The dissolution rate of quartz has been established with extensive laboratory experiments ${ }^{1-5}$ and rate equations are proposed based on those results. ${ }^{6,7}$ Hence, it is well known that with an increase in $\mathrm{pH}$ the dissolution rate of quartz increases rapidly, especially when it rises above $\mathrm{pH} 10$. Moreover, the presence of alkaline cations is known to enhance the dissolution rate of quartz. ${ }^{8,9}$ The experimentally obtained data on quartz dissolution do, however, not correspond to the recently described abnormally fast dissolution of quartz within natural rocks that have been weathered at high $\mathrm{pH}$ and $\mathrm{Mg}$-rich conditions at the surface. ${ }^{10}$ Controversially, that means that the rates obtained from the field are faster than the rates obtained from laboratory experiments. For other silicate minerals such as feldspar, a discrepancy between laboratory and field results has widely been observed, where the laboratory results almost always indicate higher rates. ${ }^{11-17}$ In recent studies on the weathering of different silicate minerals, it has been suggested that interface-coupled dissolution-precipitation processes, leading to the formation of amorphous or crystalline products, are involved in the weathering process and greatly influence the dissolution rate. ${ }^{17-21}$ These results emphasise the formation of a fluid-mineral boundary layer, whose composition differs from the bulk solution and effectively controls the coupling of the dissolution and precipitation mechanism. Laboratory experiments to determine dissolution rates have traditionally been conducted using flow-through solution conditions to reach a steady state element release, ${ }^{22}$ whereas in nature, solutions are often relatively stagnant. ${ }^{19}$ In nature limited fluid flow is proposed to slow down the weathering process through the formation of a surface layer that inhibits further surface reaction, ${ }^{21,23}$ and is therefore likely to be involved in the discrepancy between dissolution 
rates obtained from experiments and from field samples. Nanoscale analyses have also identified an amorphous layer around weathered quartz in field samples, ${ }^{24}$ that might act as a precursor for a secondary silicate phase. ${ }^{10}$ This secondary transformation possibly results in the removal of the amorphous layer hence enabling further dissolution of the underlying quartz, which may explain a higher field dissolution rate despite the initial formation of an amorphous layer. In this study, we aim to investigate the interplay between the dissolution of quartz and the formation of amorphous silica and the possibility of the formation of other secondary phases. To achieve this, we conducted atomic force microscopy (AFM) experiments at ambient conditions that allow us to observe dissolution and precipitation features in-situ on the nanoscale, from time sequences of images of the reaction progress. We used natural pure quartz to conduct the experiments with high-pH solutions to enhance the dissolution rate, and a high $\mathrm{Mg}$ concentration to promote the precipitation of a secondary Mg-phase.

High-pH, Mg-rich solutions occur in nature at ultramafic massifs due to the weathering of serpentinite which is typically associated with the dissolution of brucite, $\mathrm{Mg}(\mathrm{OH})_{2}{ }^{25,26}$ In the specific example of the Feragen Ultramafic Body in SE Norway, quartz is present within glacial deposits that partly cover the serpentinized ultramafic rock, leading to the replacement of the quartz by a nanocrystalline hydrous Mg-silicate phase. ${ }^{10}$ This resulting phase formed from a reaction between dissolved brucite and quartz, has cementing properties and is in fact similar to man-made magnesium silicate hydrate cement, also known as M-S-H cement. An understanding of conditions leading to fast quartz dissolution and the replacement of quartz by amorphous silica and eventually hydrous $\mathrm{Mg}$-silicate may be beneficial for the further development of M-S-H. Mg-based cements have been suggested as environmentally friendly cements with a much lower $\mathrm{CO}_{2}$ footprint than the widely used Portland cement. ${ }^{27}$ As the cement industry accounts for about $8 \%$ of the total anthropogenic $\mathrm{CO}_{2}$ emissions, ${ }^{28}$ and is therefore one of the largest sources of atmospheric $\mathrm{CO}_{2}$, there is an urgent need to find alternative cements. ${ }^{29,30} \mathrm{M}-\mathrm{S}-\mathrm{H}$ cement is a potential low $\mathrm{CO}_{2}$ cement that is furthermore of interest for the encapsulation of nuclear waste due to its relatively low $\mathrm{pH}$, that is, for example, beneficial for Alcontaining waste which causes corrosion problems when encapsulated in regular high-pH cements. ${ }^{31,32}$ 
However, M-S-H has not been produced on a large scale since substantial knowledge about the material is lacking and reactive $\mathrm{Si}$-sources are thought to be too expensive. Using a geomimetic approach, we explore the formation of M-S-H from quartz (an abundant mineral), which may provide new insights from which the development of M-S-H could benefit.

\section{Experimental section}

\subsection{Quartz sample and solution preparation for atomic force microscopy}

A natural transparent pure quartz crystal (from the mineral collection in the Institut für Mineralogie, University of Münster, Germany) was cut into squares of 3 x 3 x $1 \mathrm{~mm}$ with the 3 x $3 \mathrm{~mm}$ surfaces normal to the c-axis. These surfaces were polished with diamond paste until they were flat on a $\mathrm{nm}$ scale and appeared mirror-like to the naked eye. The in-situ experiments were performed in a fluid cell of a Bruker (originally Digital Instruments) Nanoscope III Multimode AFM working in contact mode at ambient temperature $\left(22 \pm 1^{\circ} \mathrm{C}\right)$ using AFM tips (Bruker, tip model NP-S10) of silicon nitride with a gold coating. Fluid could be injected into the cell through a tube connected to a syringe on one side and flowed out through an outlet tube connected to the cell. The composition of the inflow solution is known, and the outflow could be measured later. The quartz surfaces were fixed on to a Teflon ${ }^{\mathrm{TM}}$ sample holder with non-reactive conductive carbon cement.

The experimental solutions were prepared directly before the experiments from freshly prepared $\mathrm{MgCl}_{2}, \mathrm{MgSO}_{4}, \mathrm{NaOH}$ and $\mathrm{NaCl}$ solutions using reagent-grade salts (Sigma Aldrich) and deionized water (resistivity $>18 \mathrm{~m} \Omega \mathrm{cm}^{-1}$ ). Either $\mathrm{MgCl}_{2}$ or $\mathrm{MgSO}_{4}$ was used as the $\mathrm{Mg}$-source, $\mathrm{NaCl}$ was used in some solutions to control the ionic strength and $\mathrm{NaOH}$ was used to control the $\mathrm{pH}$. All solutions had an $\mathrm{MgCl}_{2}$ or $\mathrm{MgSO}_{4}$ and $\mathrm{NaOH}$ concentration on or below the solubility line of brucite to avoid its precipitation (Supporting Information Figure S-1). In total, 13 in-situ experiments were performed of which: 4 had 
changing solution composition; 3 had one solution composition during the whole experiment; and 6 initially had a high-pH solution (only $\mathrm{NaOH}+\mathrm{H}_{2} \mathrm{O}$ ) that was followed by a high-pH, Mg-rich solution (Table 1). Before the start of each experiment, an area of the surface was scanned in air. Subsequently, deionized water was injected into the fluid cell to clean the surface and adjust the AFM operating parameters. The fluid cell has a total volume of $50 \mu \mathrm{l}(\sim 40 \mu \mathrm{l}$ with the crystal in place) and during most experiments, $2 \mathrm{ml}$ of the solution were injected with a syringe after each scan (lasting $~ 70 \mathrm{~s}$ ) giving an effective flow rate of approximately $100 \mathrm{ml} \mathrm{h}^{-1}$. After initial sequential scans of approximately half an hour, the AFM tip was lifted out of contact with the surface and the fluid kept stagnant to observe the dissolution process after approximately $30 \mathrm{~min}$ or 1 hour without the influence of the scanning tip. The area scanned with the AFM tip was typically $3 \times 3,5 \times 5$ or $10 \times 10 \mu \mathrm{m}$. Occasionally smaller scan areas were chosen $(2 \times 2$ or $1 \times 1 \mu \mathrm{m})$ for closer observations. New scanning areas were frequently chosen since continuous scanning of one area influenced the soft material that formed on the surface. The obtained images were analysed with Bruker NanoScope Analysis software (version 1.50).

After each in-situ experiment, the quartz surface was removed and placed in a sealed plastic beaker with approximately $25 \mathrm{ml}$ of the corresponding experimental solution. After 20 or 40 hours, the surfaces were recovered from the solution and carefully dried by placing filter paper in contact with the edge of the surface, in order to remove the surface drop of solution by capillarity as quickly as possible and hence avoiding precipitate formation due to evaporation. The surface was then examined ex-situ with the AFM in air.

\subsection{Scanning electron microscopy}

After the experiments, scanning electron microscopy (SEM) in both secondary electron (SE) and back-scatter electron (BSE) modes were performed to image the surfaces and the precipitates and to perform chemical analysis with energy-dispersive X-ray spectroscopy (EDX), using a Hitachi SU5000 FESEM. A low acceleration voltage $(8-10 \mathrm{kV})$ was used to perform EDX on the precipitates to lower the 
interaction volume and subsequently limit the influence of the underlying quartz surface. The samples were coated with carbon before analysis.

\subsection{Raman Spectroscopy}

After the AFM experiments, Raman spectroscopy was used in an attempt to analyse reaction products. A WITec Alpha 300R confocal Raman spectrometer operating with the $488 \mathrm{~nm}$ line of a NdYAG laser was used to collect Raman spectra at the sample surfaces using a 50x magnification optical lens (numerical aperture: 0.8 ). This set up is expected to produce a depth penetration of $\sim 1 \mu \mathrm{m}$. To observe the surface, depth scans through the surface plane were taken with a $1 \mu \mathrm{m}$ step size in $\mathrm{Z}$ and $2 \mu \mathrm{m}$ in $\mathrm{x}$. A grating of 600 grooves/mm was used to maximize the intensity of the backscattered Raman signal and to allow the entire spectrum, from 150 to $3700 \mathrm{~cm}^{-1}$, to be obtained during a single measurement. An integration time of 20 seconds was used during the maps. Single spectra with improved signal to noise ratio in comparison to the depth scans were taken at the sample surface 20 times using a counting time of 5 seconds and averaged. Background removal and peak fitting to identify any additional contributions from amorphous silica-rich phases was conducted using the WITec Project Plus software (version 4.0).

\subsection{Geochemical modelling}

The hydro-geochemical software PHREEQC (version 3.4.0-12927) ${ }^{33}$ was used to calculate the chemical speciation of the initial solutions used in the AFM experiments as well as to simulate the reactions with quartz and assess the saturation state of the solutions with respect to possible precipitates. All calculations were done using the llnl.dat database. 


\section{Results and discussion}

\subsection{In-situ AFM observations of quartz in water at high $\mathrm{pH}$}

Observations in air show that before the quartz surface is in contact with water, it is smooth and only reveals randomly-placed transverse scratches (average depth $1 \mathrm{~nm}$ ) that originate from sample preparation (Figure 1a). The scratches are thin and sharp and therefore clearly visible. When deionized water comes in contact with the surface, the surface exhibits rounded forms and the scratches are less distinct, indicating surface structural rearrangements (Figure $1 b$ ). The rounded surface features consist of small mounds with a diameter of 50 to $150 \mathrm{~nm}$ and a height of about $1 \mathrm{~nm}$. This change occurs immediately on contact with water (neutral $\mathrm{pH}$ ), and no further changes can be observed in deionized water within the experimental observation time of several minutes.
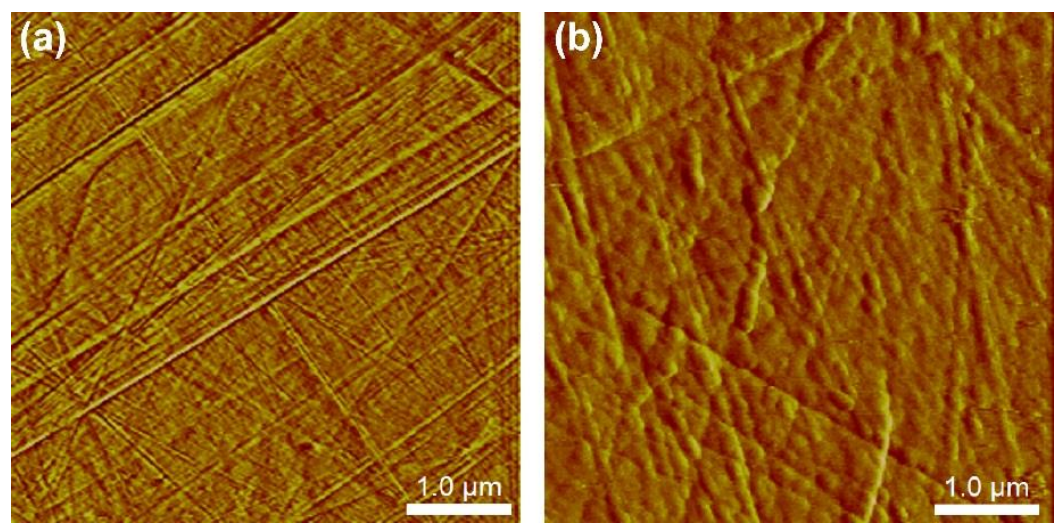

Figure 1. AFM deflection images of quartz surfaces at the beginning of the experiment scanned in air (a) and in deionized water (b). Note the small mounds or round particles over the surface that appear on the surface after contact with water and possibly indicate surface-structural rearrangement. Elongated straight lines are scratches and the result of sample preparation. The images are not from the same location on the surface. 
The influence of high-pH water, containing only deionized water and $\mathrm{NaOH}$, on the surface was investigated in order to compare any reaction with and without magnesium. Table 1 gives the details for the experimental runs. During the in-situ experiment with water at $\mathrm{pH} 10.2$, the appearance of the rounded surface features becomes more pronounced, and some of the mounds that were present on initial contact with water (Figure 1) appear to be nanoparticles or nanoparticle clusters (Figure 2a-d). The changes become apparent within a few minutes of scanning. These particles have a diameter of 100-200 nm, a height of 3 to $4 \mathrm{~nm}$ and are often aligned along the polishing scratches (Figure $2 c-d$ ). With continuous flow of the $\mathrm{pH} 10.2$ water, the particles become more pronounced and slightly larger and higher (Figure $2 e-g$ ). After about $60 \mathrm{~min}$ they reach diameters of $200-500 \mathrm{~nm}$, and heights of up to $10 \mathrm{~nm}$. The developed particles are subsequently partly or completely removed (Figure $2 e-g$ ). This indicates that they are weakly attached to the surface enabling them to be dislodged between scans $(\sim 70 \mathrm{sec})$, probably due to movement of the AFM tip. Particles start moving approximately 20 minutes after they appeared clearly on the surface, although this time varies, and some particles remain attached to the surface during the whole period of scanning. It is suggested that this process of nanoparticle removal is a form of dissolution whereby the quartz crystal loses surface nanoparticles to the solution. This random particle removal precludes a determination of a dissolution rate from successive AFM images. The implication could be that the original quartz crystal was formed by nanocluster aggregation where forces within the particles are stronger than forces between particles. This possible explanation needs further investigation but seems highly likely given our observations, and to our knowledge has not previously been reported as a dissolution mechanism.

In the experiments with water at $\mathrm{pH} 10.7$ and 12, besides the appearance of the nanoparticles, the surface is covered by a soft layer, as scanning the same area on the surface for a longer time makes the surface flatter and the surface features less pronounced due to removal of material by the tip (Figure $3 a$ ). When subsequently zooming out to scan a larger area, the previously scanned area is clearly visible as it is around $1.5 \mathrm{~nm}$ lower than the surrounding area (Figure $3 b$ ). This possibly indicates the presence of a soft gel-like layer on the surface that is weakly attached. Probably, at higher $\mathrm{pH}$, the layer is thicker, and 
the influence of the scanning forces is stronger, as this effect was not observed during the $\mathrm{pH} 10.2$ experiments.

Only in the experiments at the highest $\mathrm{pH}$ (12) were possible etch pits or deeper dissolution sites occasionally observed. These were elongated and up to approximately $90 \mathrm{~nm}$ deep.
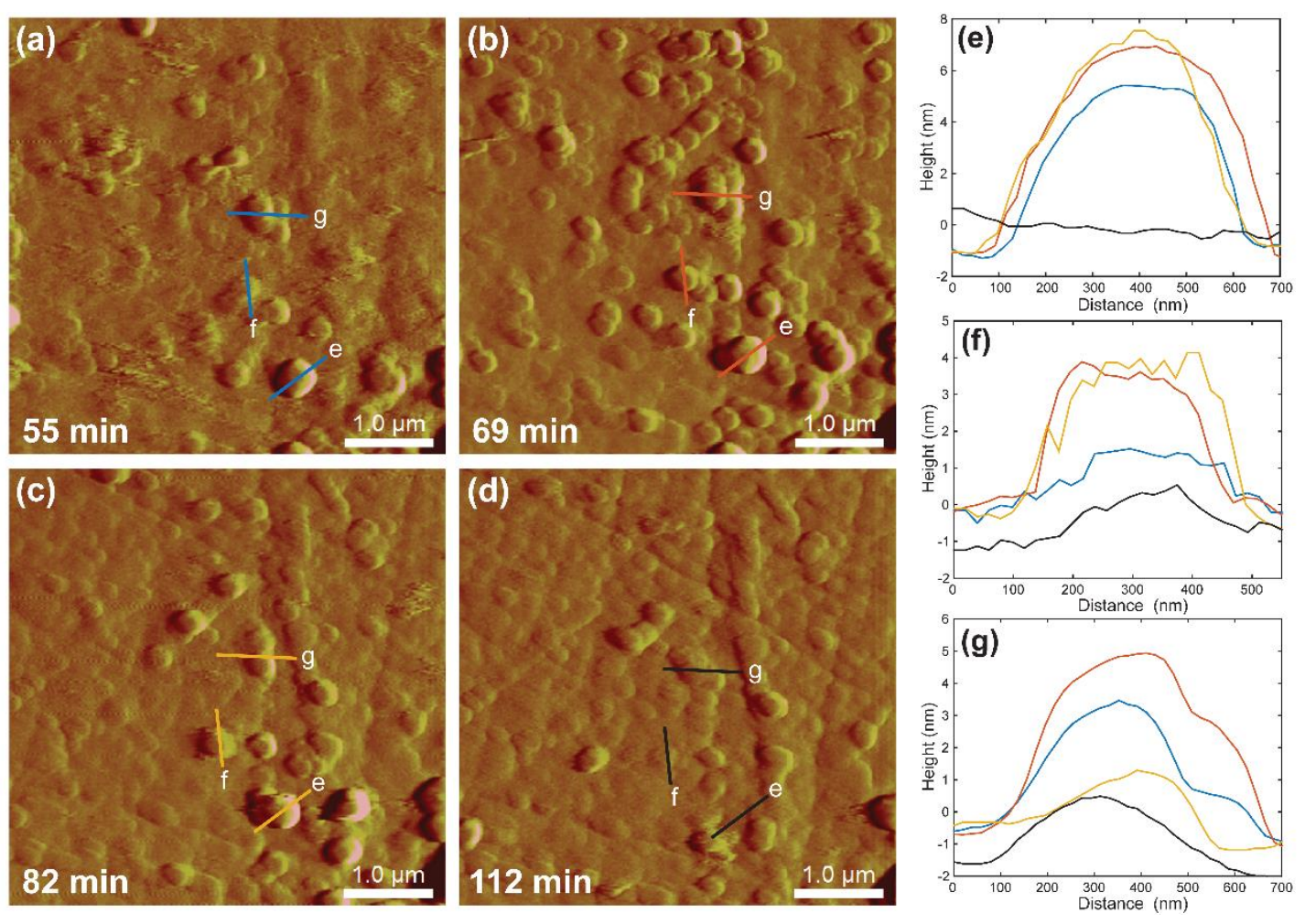

Figure 2. (a-d) Time sequence in-situ AFM deflection images of a quartz surface in $\mathrm{pH} 10.2$ solution (deionised water $+\mathrm{NaOH}$ ), without $\mathrm{Mg}$. Nanoparticles with a diameter of 150 to $350 \mathrm{~nm}$ and a height up to $8 \mathrm{~nm}$ appear on all images. (e-g) Cross-sections showing the development of the height of some nanoparticles. They all indicate that the particles first become larger, and then appear smaller or completely disappear. The locations of the sections are indicated on (a-d) with corresponding colours. The particle removal is probably enforced by the AFM tip scanning the surface and the weak attachment of the particles. 

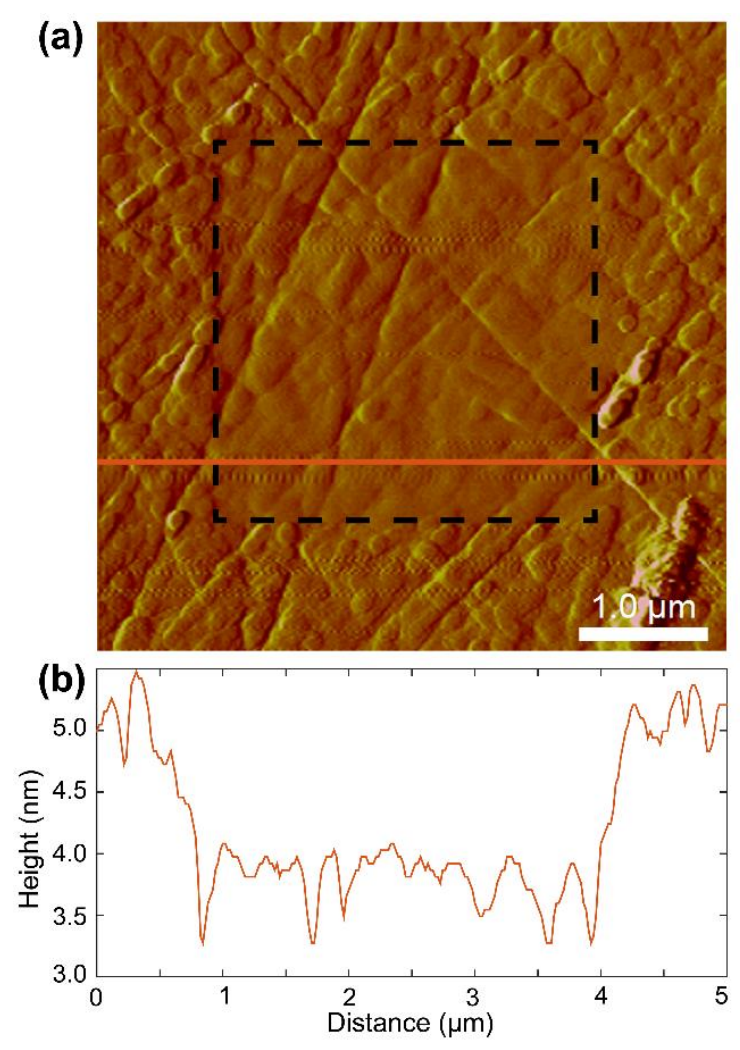

Figure 3. (a) In-situ AFM deflection image showing that a gel-like soft layer is present on the quartz surface in a solution at $\mathrm{pH} 12$ (deionised water $+\mathrm{NaOH}$ ), without $\mathrm{Mg}$. The layer is removed after a sequence of scans (black square). The image is captured about 10 minutes after the injection of a pH 12 solution after which 9 scans were made within the area delineated by the black square. The red line indicates the location of the cross-section (b), showing that the previously scanned area is about $1.5 \mathrm{~nm}$ lower than the freshly scanned area. 


\subsection{In-situ AFM observations of quartz in Mg-rich solutions at high $\mathrm{pH}$}

When high-pH and Mg-rich fluids come in contact with the quartz surface, the images show significant interference consistent with the movement of newly formed surface precipitates (Figure 4). The precipitates do not have a definite shape and lack any epitaxial relationship with the quartz surface as they are weakly attached, indicating that they are probably amorphous and gel-like. Precipitates stay absent or scarce in experiments where the $\mathrm{Mg}$ concentration is below $100 \mathrm{mM}$ (Table 1), although occasionally they occur in small amounts at a $\mathrm{Mg}$ concentration as low as $1 \mathrm{mM}$. However, at a $\mathrm{Mg}$ concentration of $100 \mathrm{mM}$, they are abundant and cover the surface (Figure 4a) but typically only on scanning after the fluid was stagnant for at least $30 \mathrm{~min}$. When scanning several times on one area, the AFM tip removes these precipitates (Figure $4 b$ ). The removal of the precipitates during scanning might be the reason why they are only abundant after a certain time without scanning and a stagnant fluid. It is thus possible that they form during flow but are not observed as they are directly removed due to continuous scanning, although it is also possible that the precipitates do not form or settle on the surface during flow. When increasing the Mg-concentration by one order of magnitude every 5 minutes, a clear boundary when the precipitates start growing is not apparent. Nevertheless, it is clear that a higher $\mathrm{Mg}$ concentration leads to more gel-like precipitates. The experiments with high $(0.3 \mathrm{M})$ and low $(0.03 \mathrm{M})$ ionic strength do not indicate a clear difference in amount of soft precipitates so no relationship between ionic strength and quartz dissolution or formation of precipitates can be defined.

The gel-like precipitates only formed when $\mathrm{Mg}$ was present in the solution, suggesting that they are a Mg phase. At present, AFM does not easily allow for phase identification and therefore the composition of the gel-like phase cannot be ascertained. However, thermodynamic considerations allow the determination of possible speciation and saturation states of the solutions with respect to potential precipitates. Here, we used PHREEQC to simulate the dissolution of quartz in our experimental solutions. The simulation results indicate that long before equilibrium with respect to quartz is reached the solutions will become supersaturated ( $\mathrm{SI}>0$ ) with respect to multiple possible Mg-silicate phases such as 
sepiolite $\left(\mathrm{Mg}_{4} \mathrm{Si}_{6} \mathrm{O}_{15}(\mathrm{OH})_{2} \cdot 6 \mathrm{H}_{2} \mathrm{O}\right)$, talc $\left(\mathrm{Mg}_{3} \mathrm{Si}_{4} \mathrm{O}_{10}(\mathrm{OH})_{2}\right)$ and chrysotile $\left(\mathrm{Mg}_{3} \mathrm{Si}_{2} \mathrm{O}_{5}(\mathrm{OH})_{4}\right)$ (Supporting

Information Table S-1 and Figure S-2). This supports the hypothesis that the precipitates that formed in our AFM experiments are potential Mg-silicate phases.

Table 1. Experimental solutions and results of AFM experiments

\begin{tabular}{|c|c|c|c|c|c|c|}
\hline Exp. ${ }^{*}$ & $\mathrm{pH}^{\dagger}$ & $\begin{array}{l}\mathrm{MgCl}_{2} \\
(\mathrm{mM})^{\dagger}\end{array}$ & $\begin{array}{c}\mathrm{MgSO}_{4} \\
(\mathrm{mM})^{\dagger}\end{array}$ & $\begin{array}{l}\mathrm{NaCl} \\
(\mathrm{mM})\end{array}$ & Results in-situ & Results ex-situ $(20-40 \mathrm{~h})^{\ddagger}$ \\
\hline 0.0 & 7.0 & - & - & - & Round surface features & - \\
\hline 1.3 & 10.2 & - & - & - & Nanoparticles & No precipitates \\
\hline 1.1 & $10.2-8.9$ & $0.1-100$ & - & - & Soft precipitates (at $\sim 100 \mathrm{mM}$ ) & Solid precipitates \\
\hline 1.2 & $10.2-8.9$ & $0.1-100$ & - & - & Soft precipitates (at $\sim 100 \mathrm{mM}$ ) & Solid precipitates \\
\hline 1.4 & 9.3 & 10 & - & $0-500$ & No changes & Few solid precipitates \\
\hline 1.5 & $9.7-8.9$ & $1-100$ & - & $0-270$ & Soft precipitates (at $\sim 100 \mathrm{mM}$ ) & Solid precipitates \\
\hline 1.6 & 9.3 & 10 & - & - & No changes & Few solid precipitates \\
\hline 1.7 & 9.3 & 10 & - & 270 & No changes & Few solid precipitates \\
\hline $2.1 \mathrm{a}$ & 10.7 & - & - & - & Nanoparticles and soft layer & - \\
\hline $2.1 \mathrm{~b}$ & 9.3 & 10 & - & - & No changes & Solid precipitates \\
\hline $2.2 \mathrm{a}$ & 10.7 & - & - & - & Nanoparticles and soft layer & - \\
\hline $2.2 \mathrm{~b}$ & 9.3 & - & 10 & - & No changes & Solid precipitates \\
\hline $2.3 \mathrm{a}$ & 10.7 & - & - & - & Nanoparticles and soft layer & - \\
\hline $2.3 b$ & 8.9 & - & 100 & - & Soft precipitates & Solid precipitates \\
\hline $2.4 \mathrm{a}$ & 10.7 & - & - & - & Nanoparticles and soft layer & - \\
\hline $2.4 \mathrm{~b}$ & 8.9 & 100 & - & - & Soft precipitates & Solid precipitates \\
\hline $2.5 \mathrm{a}$ & 12.0 & - & - & - & Nanoparticles and soft layer & - \\
\hline $2.5 \mathrm{~b}$ & 8.9 & 100 & - & - & No changes & Solid precipitates and soft layer \\
\hline $2.6 \mathrm{a}$ & 12.0 & - & - & - & Nanoparticles and soft layer & - \\
\hline $2.6 b$ & 8.9 & - & 100 & - & No changes & Solid precipitates and soft layer \\
\hline
\end{tabular}

${ }^{*} \mathrm{~b}$ is performed directly after a (which lasted 1 hour) on the same surface

${ }^{\dagger} \mathrm{pH}$ and $\mathrm{Mg}^{2+}$ concentration is always on the solubility curve of brucite

$\$$ Ex-situ experiments are performed with the last solution of the in-situ experiment 

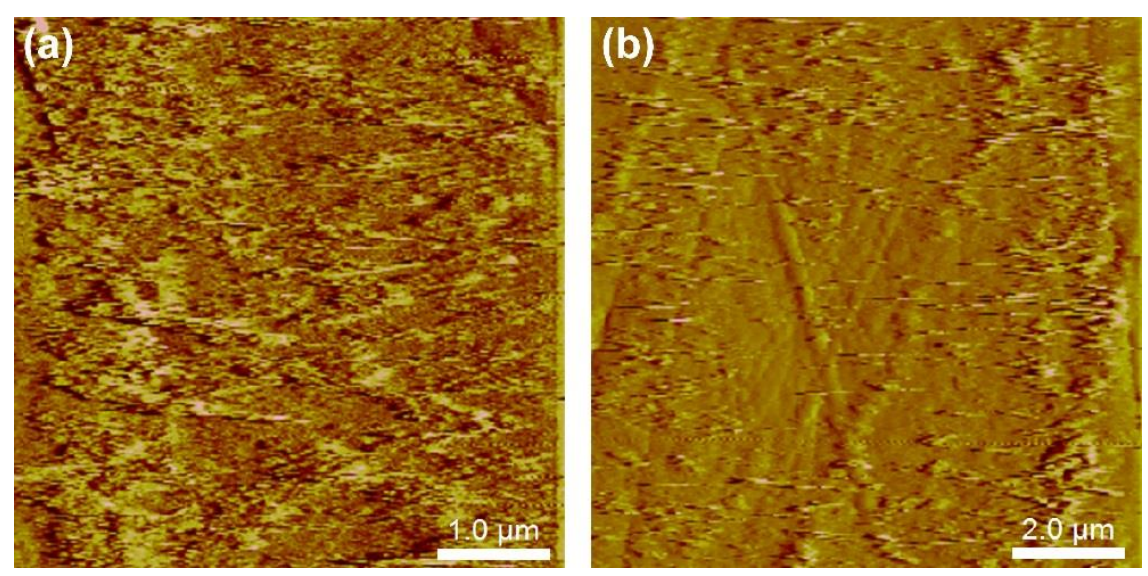

Figure 4. (a) In-situ AFM deflection image of the quartz surface that was in contact with a solution with $100 \mathrm{mM}$ $\mathrm{MgCl}_{2}$ and a $\mathrm{pH}$ of 8.9 for 2 hours. The image is captured after the fluid was stagnant for 2 hours on an area that has not been scanned previously. The image shows the high presence of a soft gel-like material that is moved by the tip. (b) A zoomed-out scan showing that after scanning the surface several times over the gel-like precipitates, the precipitates are removed and the quartz surface becomes visible again (middle of image), while the precipitates are still present around the previously un-scanned area (outer part of image).

\subsection{Ex-situ AFM observations of solid precipitates and non-solid layers}

After the quartz surfaces were in the high $\mathrm{pH}, \mathrm{Mg}$-rich experimental solutions for 20 or 40 hours and then studied in air in the AFM, larger and solid precipitates are present, where the largest are $3 \mu \mathrm{m}$ in diameter and $300 \mathrm{~nm}$ thick (Figure 5a-b). There is no significant difference between samples that were in solution for 20 and 40 hours. The precipitates are not affected by the AFM tip and can therefore be considered as well attached to the surface and solid. When the solution had a higher Mg concentration $(100 \mathrm{mM})$, many large precipitates were present. The surfaces that were in a solution with a lower $\mathrm{Mg}$ concentration $(10 \mathrm{mM})$ typically show less and smaller precipitates $(<0.5 \mu \mathrm{m}$ and only $30 \mathrm{~nm}$ thick$)$, with the exception of the surfaces that were previously in contact with high $\mathrm{pH}$ (10.7) water (Table 1), that apparently enhances the formation of precipitates presumably by enhancing quartz dissolution. No discreet precipitates could be observed on the surface that was in high $\mathrm{pH}$ water without $\mathrm{Mg}$. The 
precipitates are distributed over the surface in discreet clusters rather than as a single layer (Figure 5a), have a rounded shape without any crystalline features (such as straight edges) and typically consist of clusters of smaller rounded particles (150-200 $\mathrm{nm}$ in diameter) (Figure $5 b)$. The scratches that were the result of the polishing during sample preparation are typically still visible between the precipitates (Figure 5a-b). Since AFM cannot be used to identify the phase or analyse the precipitates chemically, they were analysed with SEM (EDX) and Raman spectroscopy.
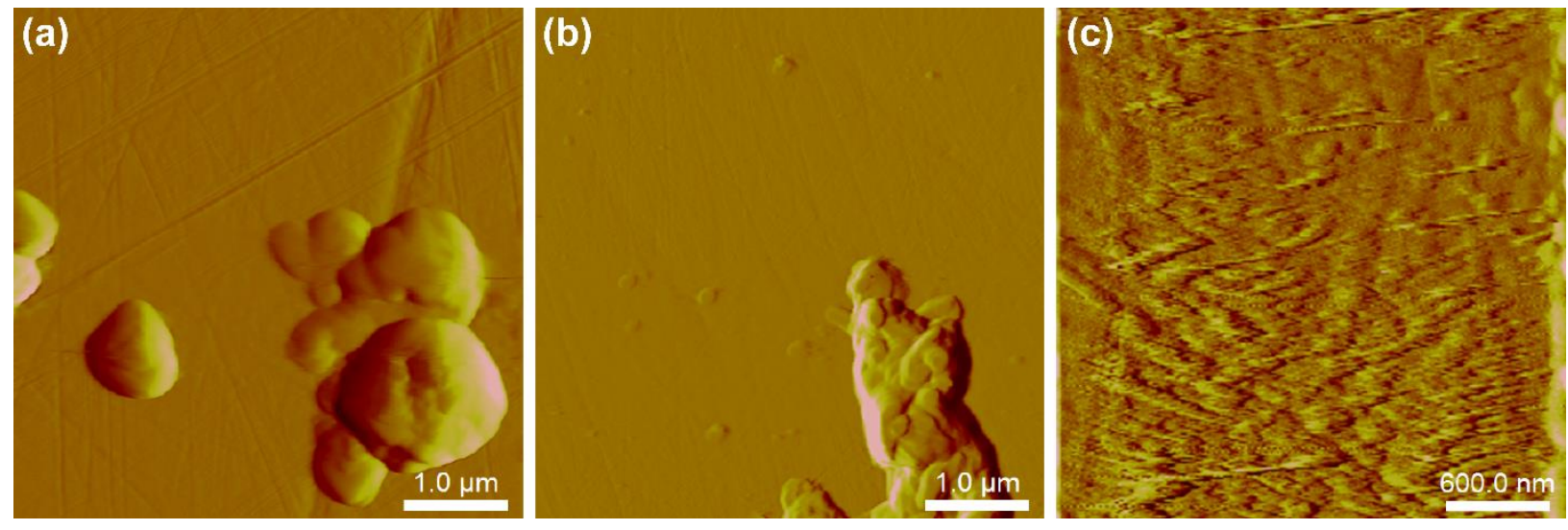

Figure 5. Ex-situ AFM deflection images of precipitates on a quartz surface, scanned in air, (a) after 40 hours in a $100 \mathrm{mM} \mathrm{MgCl} 2$ and $\mathrm{pH} 8.9$ solution, (b) after 20 hours in a $100 \mathrm{mM} \mathrm{MgCl} 2$ and $\mathrm{pH} 8.9$ solution and (c) after 1 hour in a pH 12 solution plus 20 hours in a $100 \mathrm{mM} \mathrm{MgCl}_{2}, \mathrm{pH} 8.9$ solution. Note that the precipitates in (a) and (b) occur as clusters and that the surface around them is similar to the quartz surface prior to the experiment, showing scratches from the sample preparation. The precipitates are $250 \mathrm{~nm}$ and $350 \mathrm{~nm}$ high. The wavy pattern in (c) indicates interference from the presence of a soft gel-like layer that is moved by the tip but is well enough attached to be present after the sample has been dried. Note that on the surface of (c), precipitates similar to (a) and (b) are also present.

At some places on the surface that was in $\mathrm{pH} 12$ solution before the Mg-rich solution, images show, besides the solid precipitates, wavy interference patterns and the polishing scratches are not visible (Figure 5c), indicating the occurrence of a layer of material that covers the surface. Repeated scanning partly removes the layer and reveals the scratches. This layer is likely similar to that observed during the in-situ experiments with solution of $\mathrm{pH} 10.7$ and 12 (Figure 3). Ex situ, this feature can only be observed 
at the surfaces that have been in contact with the highest $\mathrm{pH}$ (12) solution (Table 1). Probably the higher $\mathrm{pH}$ allowed for enhanced dissolution of the quartz, hence faster release of $\mathrm{Si}$, supersaturating the fluidmineral boundary layer to such an extent that a silica phase thick enough to be observed ex-situ was formed. This also implies that the dissolution rate was faster than diffusion through the fluid away from the reaction interface. However any further consideration of a quantification of reaction rates involving the coupling between dissolution and precipitation is difficult given the complex energy landscape of a mineral surface, where dissolution will be influenced by potential higher energy surface sites, such as kinks and defects and growth will only be possible where supersaturation with respect to the precipitating phase is reached. This will vary heterogeneously both spatially and temporally across a mineral surface, resulting in a complex feed-back mechanism. Any attempt at modelling or quantification has yet to be achieved. See Luttge et al. ${ }^{34}$ for a recent review of kinetic concepts towards an understanding of fluidsolid interactions.

\subsection{Identification of the precipitates}

SEM analyses of the surfaces reveals precipitates (Figure 6a) covering parts of the surface and appear as 'blobs' that correspond in size $(0.5$ and $4 \mu \mathrm{m}$ in diameter $)$ and shape with the precipitates that can be observed during the ex-situ AFM experiments (Figure 5). As also observed in AFM, the precipitates do not have crystalline features, such as straight edges. EDX analysis shows that the precipitates contain $\mathrm{Mg}$ (Figure 6b). Si is also detected in these precipitates, although it is not possible to verify that the detected Si originates from the precipitates or from the quartz surface below, which might be possible due to the interaction volume of the electron beam. However in the precipitates where $\mathrm{Mg}$ is strongly detected, $\mathrm{Si}$ is relatively lower indicating that here the ratio of $\mathrm{Mg}: \mathrm{Si}$ gives a lower $\mathrm{Si}$ count compared with the quartz surface. Brucite is thermodynamically unstable and there is no other element available to combine to form a stable $\mathrm{Mg}$ phase under the experimental conditions and so we suggest the particles analysed are highly likely to be a new Mg-Si phase, which is supported by PHREEQC 
calculations (See Supporting Information Table S-1 and Figure S-2). On the surface for which $\mathrm{MgCl}_{2}$ was used as the source of $\mathrm{Mg}$, traces of $\mathrm{Cl}$ were detected in some precipitates, while when using $\mathrm{MgSO}_{4}$ solutions, some $\mathrm{Mg}$-sulphate precipitates were found. There is however no clear difference in the Si- and Mg-rich precipitates that are shown in Figure 6 between $\mathrm{MgCl}_{2}$ and $\mathrm{MgSO}_{4}$ experiments.
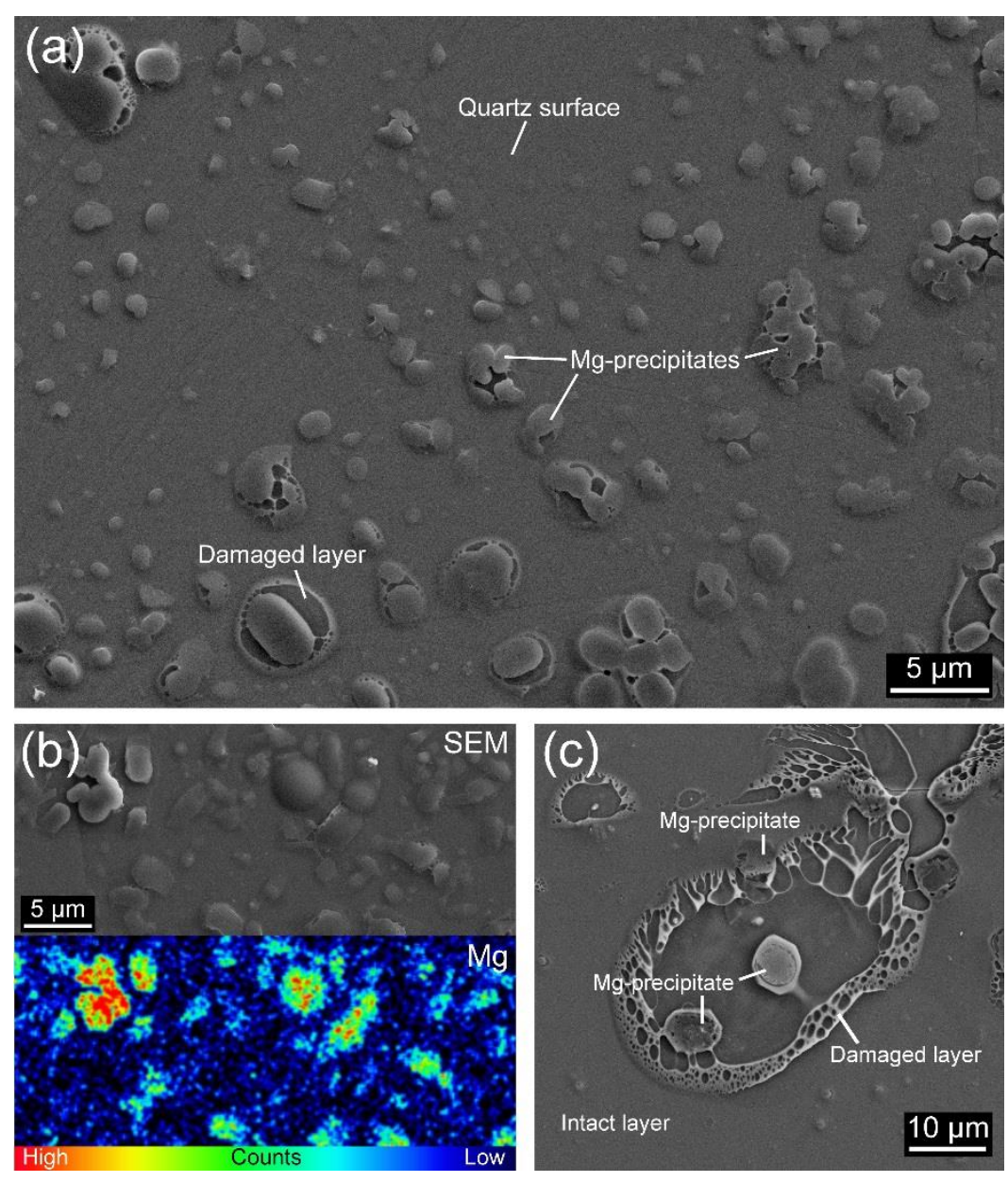

Figure 6. SEM analysis of the quartz surface after the AFM experiments, showing (a) the precipitates that formed on the quartz surface after it had been first in a $10.7 \mathrm{pH}$ solution for 1 hour during an in-situ AFM experiment and 2 hours in a $0.01 \mathrm{M} \mathrm{MgCl}_{2}$ solution at $\mathrm{pH} 9.2$, after which is was in a beaker for 20 hours in the latter solution. The 'blobs' on the surface contain $\mathrm{Mg}$ and probably also $\mathrm{Si}$. The precipitates are typically 1 to $5 \mu \mathrm{m}$ in diameter and are more abundant at the edge of the sample surface. (b) An SEM image showing the Mg precipitates with an EDX element map of the same area showing the localization of Mg in the precipitates. (c) SEM image showing that a gel-like amorphous layer is present on the surface as it is damaged by the SEM beam. Mg-rich precipitates are present within the layer. Note that this can also be observed around some of the precipitates on the lower left in (a). 
In the high $\mathrm{pH}$ experiments, the precipitates predominantly occur along the outer $50 \mu \mathrm{m}$ of the crystal edges, with only a few precipitates found in the middle of the crystal. Similarly, on the surfaces exposed to lower $\mathrm{pH}$ solutions precipitates are found mainly along the outer $10 \mu \mathrm{m}$ of the crystal edges. The correlation between precipitate formation and the edge of the crystal sheds light on the controlling processes active within the system. If precipitate formation was only dependent on the availability of $\mathrm{Mg}$ they should be homogeneously distributed across the surface. In contrast, the edges of the surface contain enhanced kink site positions allowing for preferential dissolution ${ }^{35}$ and thus have higher Si release. This indicates that conditions that promote more quartz dissolution lead to more extensive precipitation. Hence, the formation of the precipitates must be coupled to quartz dissolution. This is also reflected in the experiments that were in contact with high $\mathrm{pH}$ water (10.7 or 12) before the $\mathrm{Mg}$-rich solutions, where the precipitates are significantly more abundant than on the surfaces that were only in contact with the $\mathrm{Mg}$ rich solutions of $\mathrm{pH} 8.9$.

For the Raman spectroscopic analysis, we chose a laser with the smallest depth penetration, $<1$ $\mu \mathrm{m}$ with the small pinhole used, and highest Raman scattering efficiency to enhance the probability of generating peaks from the precipitate. Despite this no peaks other than those produced by quartz were observed in the Raman spectra with the exception of a broad band in the $\mathrm{OH}$ stretching region of the spectrum (Supporting Information Figure S-3). This is likely due to the overlap between the quartz spectrum and that expected for the precipitates based on the SEM and AFM observations. The new precipitates had a maximum height of $<400 \mathrm{~nm}$, thus the laser spot would have probed both the underlying quartz and the newly precipitated phase. Quartz has its most intense Raman band in our spectra at $468 \mathrm{~cm}^{-1}$, consistent with previous work. ${ }^{36}$ Unfortunately, this large peak overlaps the spectral area of silica ring bands in amorphous silica, the most intense band of which is observed at $488 \mathrm{~cm}^{-1}$ in Mg-rich systems. ${ }^{37}$ The low Raman scattering efficiency of an amorphous silica-like phase in comparison to quartz would thus result in the newly formed phase being swamped by the large quartz signal. However, crystalline chain or sheet Mg-silicate phases such as talc or sepiolite produce $\mathrm{Si}$-O-Si stretching modes in the region close to $650 \mathrm{~cm}^{-1},{ }^{38,39}$ which would be distinct from the quartz bands. Similarly, $\mathrm{OH}$ 
and water molecules within a specific site within a crystalline material produces sharp $\mathrm{OH}$ stretching bands. Therefore, the absence of a band close to $700 \mathrm{~cm}^{-1}$ as well as a large $\mathrm{OH}$ stretching peak implies that the precipitates probably have a hydrated and amorphous structure, as predicted by the AFM images.

\subsection{Identification of the gel-like layer}

When zooming in onto the precipitates during SEM analysis, a surface layer can be observed that is damaged by the SEM beam (Figure 6c). The damage usually starts around the precipitates, where it disintegrates and retreats away from this position upon longer exposure to the beam (Figure 6a). Such sensitivity is indicative of an amorphous layer that might have been aqueous gel-like in texture. EDX does not show any sign of elements other than $\mathrm{Si}$ and $\mathrm{O}$, suggesting a silica layer. This corresponds to the findings of the soft layer in both the in-situ (Figure 3) and ex-situ (Figure 5c) AFM experiments. The round nanoparticles that were observed in-situ are too small to observe with SEM, so it is not evident from the SEM images that the layer consists of these particles. In the SEM the layer can also clearly be observed on the surfaces that only were in contact with a solution of $\mathrm{pH} 10.7$, while during the ex-situ AFM experiments, it could only be observed on the surfaces that were in contact with a solution of $\mathrm{pH} 12$. The layer is likely to be more visible with the SEM due to the damage by the SEM beam as that creates clear edges (Figure 6c). The layer can also be observed with the SEM on the surfaces that were in contact only with the Mg-rich solution of $\mathrm{pH} 8.9$ but not as pronounced, probably indicating the layer is thinner, and only present on some parts on the surface. On these surfaces, no such layer could be observed during the in-situ or ex-situ AFM experiments (Table 1). The thickness of this layer cannot be analysed with SEM, but the combined observations of AFM and SEM suggest that a layer of amorphous silica forms at high $\mathrm{pH}$ conditions, and that an increase in $\mathrm{pH}$ results in a thicker layer. The layer is only visible at places where the $\mathrm{Mg}$ precipitates are present, suggesting that their presence is related. Like the precipitates, this layer is predominantly present at the edge of the surfaces. As quartz dissolution enhances significantly with increasing $\mathrm{pH}$, it is suggested that the layer forms due the supersaturation of the fluid-mineral 
boundary layer as a result of quartz dissolution. This is in agreement with other experiments that showed the formation of amorphous silica layers upon dissolution. Hellmann et al. ${ }^{40}$ recognised the formation of so-called 'leached layers' on feldspar surfaces under hydrothermal conditions. More recent experimental studies also confirm the presence of surface silica layers on wollastonite $\left(\mathrm{CaSiO}_{3}\right)^{18,20}$ and field studies show such a layer on weathered K-feldspar, ${ }^{13}$ weathered alkali feldspar ${ }^{21}$ and on weathered quartz. ${ }^{24}$ On the surfaces treated with the $\mathrm{pH} 12$ solution, producing the thickest layer (Figure 6), no soft precipitates could be observed during the in-situ experiments after a Mg solution was injected into the AFM cell (Table 1). This indicates that the presence of a thick layer at the sample surface might begin to passivate the surface and slow down the formation of a Mg phase in comparison to equivalent experiments at lower $\mathrm{pH}$. Nevertheless after 20 hours in a stagnant solution the solid Mg containing precipitates were present, as observed with the AFM ex-situ experiments and the SEM analyses. Amorphous silica is also expected to dissolve in high $\mathrm{pH}$ water, ${ }^{41}$ therefore the outer part of the newly-formed layer might also dissolve allowing the Si to become incorporated into the Mg-precipitates. As can be observed in Figure 6a and $c$, the Mg containing solid precipitates are embedded within the gel-like silica layer, and as mentioned above the precipitates are only present where the layer is present. It is also known that the formation of Mgsilicates typically involves gel-like precursors consisting of nanoparticles, ${ }^{42,43}$ which can transform into more crystalline products. ${ }^{44,45}$ Experiments have shown that Mg-silicates can precipitate directly from water with $\mathrm{MgCl}_{2}(\mathrm{aq})$ and $\mathrm{SiO}_{2}(\mathrm{aq})$ at room temperature if the conditions are sufficiently alkaline. ${ }^{44}$ Furthermore, it has been shown that silica fume (amorphous silica) mixed with water and $\mathrm{MgO}$, which hydrates first to brucite, forms magnesium silicate hydrate. ${ }^{32}$ This is in agreement with the results of this study, which suggest that gel-like amorphous silica is required for Mg-containing solid precipitates (likely $\mathrm{Mg}$-silicate) to form if enough soluble $\mathrm{Mg}$ is present, and that their abundance is related to the thickness of the silica layer. Quartz dissolution by the release of nanoparticles could be observed within minutes in the AFM, and the formation of soft precipitates in the presence of Mg after 30 minutes. Therefore, it is suggested that the dissolution and precipitation reactions are fast, but that in order to develop solid 
precipitates, more time and stagnant solutions are required to first form a significant amorphous silica layer from which solid Mg particles can form.

\subsection{Implications for the environment}

The mineral-fluid interface is where minerals react with the environment ${ }^{46}$ and is central to reactions occurring in the Earth. The results of experiments discussed here indicate the coupling between the dissolution of a quartz surface and the precipitation of a new Mg-containing phase. This reaction coupling occurs from within a boundary layer at the mineral-fluid interface where the fluid can become supersaturated with a new phase that can then precipitate. ${ }^{47}$ Such interface-coupled dissolution-precipitation reactions have been previously described from AFM experiments ${ }^{19}$ as well as larger scale hydrothermal experiments ${ }^{48-50}$ and often with reference to potential environmental remediation, such as sequestration of atmospheric $\mathrm{CO}_{2}{ }^{51,52}$ or removal of excess $\mathrm{PO}_{4}$ from eutrophic waters resulting from the overuse of phosphate fertilizers in agriculture, ${ }^{53}$ as well as toxic element sequestration. ${ }^{54-56} \mathrm{M}-\mathrm{S}-\mathrm{H}$, a Mg-silicate cement, is a practical environmentally friendly cement that furthermore could be highly suitable for the encapsulation of nuclear waste,,$^{31,32}$ but whose development is limited by the need for cost-inefficient and limited silica fume. The new direct observations presented here, which show the formation of $\mathrm{Mg}$-silicates as a result of the dissolution of widely available quartz (in the form of sand) at ambient temperatures, may therefore be fundamental knowledge leading to the production of $\mathrm{Mg}$-silicate cement.

\section{Acknowledgements}

This project has received funding from the European Union's Horizon 2020 research and innovation programme under grant agreement No 642976 (NanoHeal ITN). D.K. Dysthe is thanked for 
supporting this study. H.A. acknowledges funding from the Humboldt foundation to make international collaboration of this kind possible.

\section{References}

(1) Knauss, K. G.; Wolery, T. J. The Dissolution Kinetics of Quartz as a Function of PH and Time at 70 C. Geochim. Cosmochim. Acta 1988, 52 (1), 43-53.

(2) Brady, P. V.; Walther, J. V. Kinetics of Quartz Dissolution at Low Temperatures. Chem. Geol. 1990, $82(\mathrm{C}), 253-264$.

(3) Dove, P. M. The Dissolution Kinetics of Quartz in Aqueous Mixed Cation Solutions. Geochim. Cosmochim. Acta 1999, 63 (22), 3715-3727.

(4) House, W. A.; Orr, D. R. Investigation of the PH Dependence of the Kinetics of Quartz Dissolution at $25^{\circ}$ C. J. Chem. Soc. Faraday Trans. 1992, 88 (2), 233-241.

(5) Rimstidt, J. D.; Barnes, H. L. The Kinetics of Silica-Water Reactions. Geochim. Cosmochim. Acta 1980, 44 (11), 1-47.

(6) Bickmore, B. R.; Wheeler, J. C.; Bates, B.; Nagy, K. L.; Eggett, D. L. Reaction Pathways for Quartz Dissolution Determined by Statistical and Graphical Analysis of Macroscopic Experimental Data. Geochim. Cosmochim. Acta 2008, 72 (18), 4521-4536.

(7) Rimstidt, J. D. Rate Equations for Sodium Catalyzed Quartz Dissolution. Geochim. Cosmochim. Acta 2015, 167, 195-204.

(8) Dove, P. M.; Nix, C. J. The Influence of the Alkaline Earth Cations, Magnesium, Calcium, and Barium on the Dissolution Kinetics of Quartz. Geochim. Cosmochim. Acta 1997, 61 (16), 33293340.

(9) Dove, P. M.; Elston, S. F. Dissolution Kinetics of Quartz in Sodium Chloride Solutions: Analysis of Existing Data and a Rate Model for $25^{\circ} \mathrm{C}$. Geochim. Cosmochim. Acta 1992, 56, 4147-4156.

(10) de Ruiter, L.; Austrheim, H. Formation of Magnesium Silicate Hydrate Cement in Nature. J. Geol. 
Soc. London. 2018, 175 (2), 308-320.

(11) White, A. F.; Brantley, S. L. The Effect of Time on the Weathering of Silicate Minerals: Why Do Weathering Rates Differ in the Laboratory and Field? Chem. Geol. 2003, 202 (3-4), 479-506.

(12) Gruber, C.; Zhu, C.; Georg, R. B.; Zakon, Y.; Ganor, J. Resolving the Gap between Laboratory and Field Rates of Feldspar Weathering. Geochim. Cosmochim. Acta 2014, 147, 90-106.

(13) Zhu, C.; Veblen, D. R.; Blum, A. E.; Chipera, S. J. Naturally Weathered Feldspar Surfaces in the Navajo Sandstone Aquifer, Black Mesa, Arizona: Electron Microscopic Characterization. Geochim. Cosmochim. Acta 2006, 70 (18), 4600-4616.

(14) Moore, J.; Lichtner, P. C.; White, A. F.; Brantley, S. L. Using a Reactive Transport Model to Elucidate Differences between Laboratory and Field Dissolution Rates in Regolith. Geochim. Cosmochim. Acta 2012, 93, 235-261.

(15) White, A. F.; Bullen, T. D.; Schulz, M. S.; Blum, A. E.; Huntington, T. G.; Peters, N. E. Differential Rates of Feldspar Weathering in Granitic Regoliths. Geochim. Cosmochim. Acta 2001, 65 (6), 847869.

(16) Oelkers, E. H. General Kinetic Description of Multioxide Silicate Mineral and Glass Dissolution. Geochim. Cosmochim. Acta 2001, 65 (21), 3703-3719.

(17) Hellmann, R.; Wirth, R.; Daval, D.; Barnes, J. P.; Penisson, J. M.; Tisserand, D.; Epicier, T.; Florin, B.; Hervig, R. L. Unifying Natural and Laboratory Chemical Weathering with Interfacial Dissolution-Reprecipitation: A Study Based on the Nanometer-Scale Chemistry of Fluid-Silicate Interfaces. Chem. Geol. 2012, 294-295, 203-216.

(18) Ruiz-Agudo, E.; Putnis, C. V.; Rodriguez-Navarro, C.; Putnis, A. Mechanism of Leached Layer Formation during Chemical Weathering of Silicate Minerals. Geology 2012, 40 (10), 947-950.

(19) Ruiz-Agudo, E.; Putnis, C. V.; Putnis, A. Coupled Dissolution and Precipitation at Mineral-fluid Interfaces. Chem. Geol. 2014, 383, 132-146.

(20) Ruiz-Agudo, E.; King, H. E.; Patiño-López, L. D.; Putnis, C. V.; Geisler, T.; Rodriguez-Navarro, C.; Putnis, A. Control of Silicate Weathering by Interface-Coupled Dissolution-Precipitation 
Processes at the Mineral-Solution Interface. Geology 2016, 44 (7), 567-570.

(21) Daval, D.; Calvaruso, C.; Guyot, F.; Turpault, M. P. Time-Dependent Feldspar Dissolution Rates Resulting from Surface Passivation: Experimental Evidence and Geochemical Implications. Earth Planet. Sci. Lett. 2018, 498, 226-236.

Oelkers, E. H.; Schott, J.; Devidal, J. L. The Effect of Aluminum, PH, and Chemical Affinity on the Rates of Aluminosilicate Dissolution Reactions. Geochim. Cosmochim. Acta 1994, 58 (9), 20112024.

(23) Daval, D.; Sissmann, O.; Menguy, N.; Saldi, G. D.; Guyot, F.; Martinez, I.; Corvisier, J.; Garcia, B.; Machouk, I.; Knauss, K. G.; et al. Influence of Amorphous Silica Layer Formation on the Dissolution Rate of Olivine at $90^{\circ} \mathrm{C}$ and Elevated PCO2. Chem. Geol. 2011, 284 (1-2), 193-209.

(24) Pope, G. A. Newly Discovered Submicron-Scale Weathering in Quartz: Geographical Implications. Prof. Geogr. 1995, 47 (4), 375-387.

(25) Beinlich, A.; Austrheim, H. In Situ Sequestration of Atmospheric CO2 at Low Temperature and Surface Cracking of Serpentinized Peridotite in Mine Shafts. Chem. Geol. 2012, 332-333, 32-44.

(26) Ulven, O. I.; Beinlich, A.; Hövelmann, J.; Austrheim, H.; Jamtveit, B. Subarctic Physicochemical Weathering of Serpentinized Peridotite. Earth Planet. Sci. Lett. 2017, 468, 11-26.

(27) Walling, S. A.; Provis, J. L. Magnesia-Based Cements: A Journey of 150 Years, and Cements for the Future? Chem. Rev. 2016, 116 (7), 4170-4204.

(28) Andrew, R. M. Global CO 2 Emissions from Cement Production. Earth Syst. Sci. Data 2018, 10, $195-217$.

(29) Schneider, M.; Romer, M.; Tschudin, M.; Bolio, H. Sustainable Cement Production - Present and Future. Cem. Concr. Res. 2011, 41 (7), 642-650.

(30) Imbabi, M. S.; Carrigan, C.; McKenna, S. Trends and Developments in Green Cement and Concrete Technology. Int. J. Sustain. Built Environ. 2012, 1 (2), 194-216.

(31) Zhang, T.; Cheeseman, C. R.; Vandeperre, L. J. Development of Low PH Cement Systems Forming Magnesium Silicate Hydrate (M-S-H). Cem. Concr. Res. 2011, 41 (4), 439-442. 

Encapsulating Problematic Aluminium Containing Wastes. J. Sustain. Cem. Mater. 2012, 1 (1-2), 34-45.

(33) Parkhurst, B. D. L.; Appelo, C. a J. User's Guide To PHREEQC (Version 2) - a Computer Program for Speciation, and Inverse Geochemical Calculations. US Geol. Surv. - Water-Resources Investig. Reports 1999, 99-4259.

(34) Luttge, A.; Arvidson, R. S.; Fischer, C.; Kurganskaya, I. Kinetic concepts for quantitative prediction of fluid-solid interaction. Chem. Geol. 2019, 504, 216-235.

(35) Luttge, A.; Arvidson, R. S. Kink Site Reaction Kinetics: A New Model Unifies Crystal Dissolution and Growth Theory. In Geochimica et Cosmochimica Acta; 2010; Vol. 74, pp A645--A645.

(36) Krishnamurti, D. The Raman Spectrum of Quartz and Its Interpretation. Proc. Indian Acad. Sci. 1958, 47, 276-291.

(37) King, H. E.; Plümper, O.; Geisler, T.; Putnis, A. Experimental Investigations into the Silicification of Olivine: Implications for the Reaction Mechanism and Acid Neutralization. Am. Mineral. 2011, $96(10), 1503-1511$.

(38) Blaha, J. J.; Rosasco, G. J. Raman Microprobe Spectra of Individual Microcrystals and Fibers of Talc, Tremolite, and Related Silicate Minerals. Anal. Chem. 1978, 50 (7), 892-896.

(39) Kloprogge, J. T. Raman Spectroscopy of Clay Minerals. Dev. Clay Sci. 2017, 8, 150-199.

(40) Hellmann, R.; Eggleston, C. M.; Hochella, M. F.; Crerar, D. A. The Formation of Leached Layers on Albit. Geochim. Cosmochim. Acta 1990, 54, 1267-1281.

(41) Iler, R. K. The Chemistry of Silica: Solubility, Polymerization, Colloid and Surface Properties, and Biochemistry; Wiley, New York, 1979.

(42) Steefel, C. I.; Van Cappellen, P. A New Kinetic Approach to Modeling Water-Rock Interaction: The Role of Nucleation, Precursors, and Ostwald Ripening. Geochim. Cosmochim. Acta 1990, 54 (10), 2657-2677.

(43) Baldermann, A.; Mavromatis, V.; Frick, P. M.; Dietzel, M. Effect of Aqueous Si/Mg Ratio and PH 
on the Nucleation and Growth of Sepiolite at $25^{\circ}$ C. Geochim. Cosmochim. Acta 2018, 227, 211226.

(44) Tosca, N. J.; Masterson, A. L. Chemical Controls on Incipient Mg-Silicate Crystallization at $25^{\circ} \mathrm{C}$ : Implications for Early and Late Diagenesis. Clay Miner. 2014, 49 (2), 165-194.

(45) Tosca, N. Geochemical Pathways to Mg-Silicate Formation. Magnesian Clays Charact. Orig. Appl. 2015, 2, 283-330.

(46) Putnis, C. V.; Ruiz-Agudo, E. The Mineral-Water Interface: Where Minerals React with the Environment. Elements 2013, 9 (3), 177-182.

(47) Putnis, A.; Putnis, C. V. The Mechanism of Reequilibration of Solids in the Presence of a Fluid Phase. J. Solid State Chem. 2007, 180 (5), 1783-1786.

(48) Kasioptas, A.; Geisler, T.; Putnis, C. V.; Perdikouri, C.; Putnis, A. Crystal Growth of Apatite by Replacement of an Aragonite Precursor. J. Cryst. Growth 2010, 312 (16-17), 2431-2440.

(49) Pedrosa, E. T.; Putnis, C. V.; Putnis, A. The Pseudomorphic Replacement of Marble by Apatite: The Role of Fluid Composition. Chem. Geol. 2016, 425, 1-11.

(50) Xia, F.; Brugger, J.; Chen, G.; Ngothai, Y.; O’Neill, B.; Putnis, A.; Pring, A. Mechanism and Kinetics of Pseudomorphic Mineral Replacement Reactions: A Case Study of the Replacement of Pentlandite by Violarite. Geochim. Cosmochim. Acta 2009, 73 (7), 1945-1969.

(51) Oelkers, E. H.; Gislason, S. R.; Matter, J. Mineral Carbonation of CO2. Elements 2008, 4 (5), $333-$ 337.

(52) Hövelmann, J.; Putnis, C. V.; Ruiz-Agudo, E.; Austrheim, H. Direct Nanoscale Observations of $\mathrm{CO} 2$ Sequestration during Brucite $[\mathrm{Mg}(\mathrm{OH}) 2]$ Dissolution. Environ. Sci. Technol. 2012, 46 (9), $5253-5260$.

(53) Wang, L.; Ruiz-Agudo, E.; Putnis, C. V.; Menneken, M.; Putnis, A. Kinetics of Calcium Phosphate Nucleation and Growth on Calcite: Implications for Predicting the Fate of Dissolved Phosphate Species in Alkaline Soils. Environ. Sci. Technol. 2012, 46 (2), 834-842.

(54) Putnis, C. V.; Renard, F.; King, H. E.; Montes-Hernandez, G.; Ruiz-Agudo, E. Sequestration of 
Selenium on Calcite Surfaces Revealed by Nanoscale Imaging. Environ. Sci. Technol. 2013, 47 (23), $13469-13476$.

(55) Renard, F.; Putnis, C. V.; Montes-Hernandez, G.; Ruiz-Agudo, E.; Hovelmann, J.; Sarret, G. Interactions of Arsenic with Calcite Surfaces Revealed by in Situ Nanoscale Imaging. Geochim. Cosmochim. Acta 2015, 159, 61-79.

(56) Hövelmann, J.; Putnis, C.; Benning, L. Metal Sequestration through Coupled Dissolutionprecipitation at the Brucite-water Interface. Minerals 2018, 8 (8), 346. 